Original Research Paper

\title{
Flavonoids from the Zizania latifolia Bracts: Extraction Optimization, Antioxidant Activity and Exploration in Strawberry Preservation
}

\author{
${ }^{1}$ Tong Wang, ${ }^{1}$ Yuzhu Zhang, ${ }^{1,2}$ Lijie Ben, ${ }^{1}$ Chenxin Zhai, ${ }^{1}$ Ying Lv, ${ }^{1 *}$ Yang Zhang and ${ }^{1 *}$ Lixue Zheng \\ ${ }^{1}$ School of Biology and Food Engineering, Changshu Institute of Technology, Changshu 215500, Jiangsu, China \\ ${ }^{2}$ School of Medical Instrument and Food Engineering, \\ University of Shanghai for Science and Technology, Shanghai 200093, Shanghai, China
}

Article history

Received: 06-02-2021

Revised: 11-03-2021

Accepted: 15-03-2021

Corresponding Author:

Yang Zhang

School of Biology and Food

Engineering, Changshu

Institute of Technology,

Changshu 215500, Jiangsu,

China

Email: zhangyang@cslg.edu.cn

Lixue Zheng

School of Biology and Food

Engineering, Changshu

Institute of Technology,

Changshu 215500, Jiangsu,

China

Email: lixue9418@163.com

\begin{abstract}
Zizania latifolia bracts are Z. latifolia-based agricultural waste materials, distributed in various parts of the world. In the current study, the Response Surface Method (RSM) was used to optimize the cellulaseassisted extraction of Total Flavonoids from Z. latifolia bracts (TFZB). Then, the in vitro antioxidant capacity and the potential effect on strawberry preservation were assessed. The results showed that the optimal conditions for extracting TFZB was: Solid-to-liquid ratio of 1: $40 \mathrm{~g} / \mathrm{mL}$; ethanol concentration of $60 \%(\mathrm{v} / \mathrm{v})$; cellulase dosage of $0.4 \%(\mathrm{w} / \mathrm{w})$; incubation time of $2 \mathrm{~h}$. Under these conditions, the yield of TFZB reached $0.49 \pm 0.01 \%$. TFZB exerted certain antioxidant capacity. The free radicalscavenging rates against hydroxyl and DPPH radicals were $86 \pm 1.32 \%$ and $90 \pm 1.6 \%$ respectively at the concentration of $1.6 \mathrm{mg} / \mathrm{mL}$ and TFZB also exerted reducing power on $\mathrm{Fe}^{3+}$. Finally, the potential of TFZB on strawberry preservation was investigated from three aspects: Weightlessness rate, rotting rate and $\mathrm{Vc}$ content. It was found that the above-mentioned profiles were all improved after the strawberries sprayed with TFZB solution during the storage period. This study suggested that the TFZB may be developed as a novel antioxidant and fruits preservative, providing an evidence for the further utilization of $Z$. latifolia bracts.
\end{abstract}

Keywords: Zizania latifolia Bracts, Total Flavonoids, Cellulase-Assisted Extraction, Antioxidant Activity, Strawberry Preservation

\section{Introduction}

Zizania latifolia is a perennial herb, native to China and Southeast Asia (Zhang et al., 2009). In China, the planting area of Z. latifolia is about $70,000 \mathrm{hm}^{2}$, which is the second largest aquatic vegetable next to the lotus root. In China, Z. latifolia is generally distributed along the Yangtze River and Huaihe River (Jiang et al., 2016). Z. latifolia is mainly composed of rhizomes and bracts. The rhizomes are used for daily consumption. In addition to the dietary characteristics, the rhizomes of $Z$. latifolia are rich in various physiologically active compounds, including dietary fibers, vitamins, minerals and phenolic compounds (Yan et al., 2018), which could produce a marked effect in reducing the risk of noncommunicable diseases, such as obesity, diabetes and cardiovascular diseases (Shao et al., 2014). At present, some reports on Z. latifolia are mostly focused on nutrients and health benefits (Surendiran et al., 2014). By consulting the literatures, we found that many plant bracts also contain certain physiologically active substances. However, there is little information on $Z$. latifolia bracts, most of which are discarded as agricultural wastes and their full and effective utilizations have not been constructed and realized.

Flavonoids are widely distributed in plants as secondary metabolites (Zakaryan et al., 2017). Because of medicinal values, scholars from all over the world have launched different degrees of researches on flavonoids, some of them focused on the extraction of flavonoids from agricultural waste materials and further explored the biological activities. For example, (Zhang et al., 2019) extracted Flavonoids from Corn Bracts (FCB) and found that FCB has strong antioxidant capacity and certain inhibitory effects on gram-positive bacteria. Winarsi and Yuniaty (2019) found that cardamom roots are rich in 
flavonoids, which have the potential to be developed as the ingredients for antioxidant functional foods. Flavonoids from camphor leaves were extracted (Liu et al., 2019a) and were found to possess strong potentials to be consumed as natural antioxidants. Cui et al. (2020) found that flavonoids from Morus alba L. leaves (MLF) has excellent antibacterial and antioxidant effects, another surprising discovery was that the shelf life of chilled meat treated with MLF was extended from 6 days to 9 days. In addition, many researchers have also carried out the studies on the application of flavonoids from plants in food preservation and the results showed that natural flavonoids usually elicit positive effects on food preservation (Liu et al., 2019b).

Herein, Total Flavonoids from Z. latifolia Bracts (TFZB) were extracted by Cellulase-Assisted extraction (CAT) for the first time. CAT has the advantages of higher efficiency in flavonoids extraction from bracts in which cellulose can be degraded by cellulose, facilitating the release of cellular flavonoids (Huang et al., 2016). In addition, CAT has good environmental compatibility, low energy consumption and simplified operation (Chen and Yen, 2007). Then, in present work, the antioxidant activities of TFZB were surveyed. Besides, the application of TFZB on the preservation of strawberry were investigated by referring the changes of weightlessness rate, rotting rate and Vitamin $\mathrm{C}(\mathrm{Vc})$ content during storage time for the first time. All the above investigations were used to estimate the potential of TFZB to be utilized in food and relating industries.

\section{Materials and Methods}

\section{Materials}

The Z. latifolia bracts and strawberries used in the tests were collected from Datang Ecological Agriculture Development Co., Ltd. (Jiangsu, Changshu, China). Rutin standard was purchased from Yuanye Biotechnology Co., Ltd. (Shanghai, China) and other chemical reagents were all analytical or chemical purity.

\section{TFZB Extraction}

\section{Cellulase-Assisted Extraction (CAE)}

The extraction of TFZB was referred to the previously reported method (Zhang et al., 2019). The washed fresh $Z$. latifolia bracts were dried at a constant temperature of $60^{\circ} \mathrm{C}$ for 2 days and crushed to a particle size of 40 mesh and stored at $4^{\circ} \mathrm{C}$. Powders of Z. latifolia bracts were immersed in Disodium Hydrogen Phosphate (DHP)-citric acid buffer solution ( $\mathrm{pH}=5$, a fixed solidto-liquid ratio of $1 \mathrm{~g}$ : $20 \mathrm{~mL}$ ), then certain amounts of cellulase were added $(0.2 \sim 0.6 \%, \mathrm{w} / \mathrm{w})$ to be incubated at $40^{\circ} \mathrm{C}$ for certain time $(0.5 \sim 1.5 \mathrm{~h})$. After enzymatic hydrolysis, residual cellulose was inactivated at $90^{\circ} \mathrm{C}$ for
10 min. Lastly, certain amounts of anhydrous ethanol and deionized water were added to adjust the system to be certain concentrations of ethanol $(40 \sim 90 \%$, v/v) and certain ratios of solid-to-liquid (1: $20 \mathrm{~g} / \mathrm{mL} \sim 1: 60$ $\mathrm{g} / \mathrm{mL}$ ), followed by $2 \mathrm{~h}$-extraction at $80^{\circ} \mathrm{C}$. The particulate matter in the mixture was removed by centrifugation and the supernatant was taken to determine the content of total flavonoids.

Extraction yield of TFZB was expressed as below:

$Y(\%)=\frac{C \times V}{M} \times 100$

Where:

$C=$ Concentration of total flavonoids in TFZB $(\mathrm{mg} / \mathrm{mL})$

$V=$ Volume of filtrate $(\mathrm{mL})$

$M=$ Weight of Z. latifolia bracts powders (mg)

\section{Total Flavonoids Content in TFZB}

Rutin was used as the standard to determine the flavonoids content in TFZB, the $\mathrm{NaNO}_{2}-\mathrm{Al}\left(\mathrm{NO}_{3}\right)_{3}-$ $\mathrm{NaOH}$ colorimetric method was slightly modified on the basis of the method previously mentioned (Bai et al., 2015). The specific steps in this assay were as follows: $1 \mathrm{~mL}$ of filtrate was added into a colorimetric tube, then $0.3 \mathrm{~mL}$ of $5 \% \mathrm{NaNO}_{2}, 0.3 \mathrm{~mL}$ of $10 \% \mathrm{Al}\left(\mathrm{NO}_{3}\right)_{3}$ and $4 \mathrm{~mL}$ of $1 \mathrm{~mol} / \mathrm{L} \mathrm{NaOH}$ solutions were added in turn, shook well and let it stand for $6 \mathrm{~min}$. Finally, the mixture was attenuated to $10 \mathrm{~mL}$ with $60 \%$ (v/v) ethanol, after $15 \mathrm{~min}$, the absorbance was determined at $510 \mathrm{~nm}$, which was put into the equation of regression using rutin as the standard to calculate the total flavonoids content in TFZB. The equation of regression was expressed as below:

$A=2.0708 C-0.0042\left(R^{2}=0.9995\right)$

Where:

$A=$ The absorbance

$C=$ Flavonoids content in TFZB $(\mathrm{mg} / \mathrm{mL})$

\section{Experimental Design of Response Surface Optimization}

Before the response surface optimization, the singlefactor experiments were used to evaluate the optimal level of the three factors of ethanol concentration (40 80\%, v/v), cellulase dosage $(0.2 \sim 0.6 \%, \mathrm{w} / \mathrm{w})$ and solid-to-liquid ratio $(1: 20 \sim 1: 60, \mathrm{~g} / \mathrm{mL})$ on TFZB extraction yield. Then, response surface optimization (Sheng et al., 2013) was designed according to the results of single-factor experiment using Box-Behnken design via Design-Expert V8.0.6.1 software (Table 1). 
Table 1: The code and actual levels of three factors used in the RSM

\begin{tabular}{llll}
\hline & Level & \\
& ---------- \\
Independent variable & -1 & 0 & 1 \\
\hline$X_{1}:$ Cellulase amount $(w / w, \%)$ & 0.2 & 0.4 & 0.6 \\
$X_{2}:$ Ethanol concentration $(\mathrm{v} / \mathrm{v}, \%)$ & 40 & 60 & 80 \\
$X_{3}$ : Solid-to-liquid ratio $(\mathrm{g} / \mathrm{mL})$ & $1: 20$ & $1: 40$ & $1: 60$ \\
\hline
\end{tabular}

\section{Purification of TFZB}

TFZB was purified by column chromatography loaded with D101 macroporous resin (Zhang et al., 2007). Before experiment, the resin was immersed in $95 \%(\mathrm{v} / \mathrm{v})$ ethanol for $24 \mathrm{~h}$, then washed with distilled water for several times to remove the residual ethanol. Afterwards, the treated resin was loaded on a column with volume of $300 \mathrm{~mL}$ and diameter to height ratio of 1: 8 . The purification parameters were as follows: Loading amount of $5.0 \mathrm{~g}$ of dried TFZB powders; eluent of $60 \%$ ethanol $(\mathrm{v} / \mathrm{v})$; velocity of 2.0 $\mathrm{mL} / \mathrm{min}$. After purification, the content of total flavonoids in TFZB increased from $35 \pm 3.2$ to $59 \pm 1.9 \%$.

\section{In vitro Antioxidant Activity of TFZB}

\section{DPPH Radical-Scavenging Capacity}

The DPPH radical-scavenging ability was evaluated by the previously mentioned method (Chen and Yen, 2007) with slightly modifications. As much as $2 \mathrm{~mL}$ of TFZB solution $(0.2 \sim 1.0 \mathrm{mg} / \mathrm{mL})$ and $2 \mathrm{~mL}$ of 0.2 $\mathrm{mmol} / \mathrm{L}$ DPPH solution (dissolved in $90 \%$ ethanol) were mixed and incubated in the dark at $37^{\circ} \mathrm{C}$ for $20 \mathrm{~min}$, followed by measuring the absorbance at $517 \mathrm{~nm}(A s)$ and each process was repeated three times. The reaction system without DPPH solution was used as normal control (Ac) and the system without TFZB was employed as blank solution $\left(A_{0}\right) . \quad V_{C}$ solutions of different concentrations $(0.2 \sim 1.0 \mathrm{mg} / \mathrm{mL})$ were used as positive control. The ability to scavenge DPPH radical was calculated by the following formula:

$$
D P P H \text { Radical Scavenging rate }(\%)=\frac{A s-A c}{A o} \times 100
$$

\section{Hydroxyl Radical-Scavenging Capacity}

The hydroxyl radical-scavenging ability of TFZB was carried out by method of phenanthroline- $\mathrm{Fe}^{2+}$ and was slightly modified on the basis of the method previously mentioned (Chen and Yen, 2007). About $2 \mathrm{~mL}$ of TFZB solution $(0.5 \sim 2.0 \mathrm{mg} / \mathrm{mL})$ was mixed with $1 \mathrm{~mL}$ of 0.75 $\mathrm{mmol} / \mathrm{L} \mathrm{FeSO}_{4} \cdot 7 \mathrm{H}_{2} \mathrm{O}, 1 \mathrm{~mL}$ of $0.01 \% \mathrm{H}_{2} \mathrm{O}_{2}$ and $1 \mathrm{~mL}$ of $0.75 \mathrm{mmol} / \mathrm{L}$ phenanthroline (dissolved in ethanol solution) in turn. The reaction system was placed at $37^{\circ} \mathrm{C}$ for $60 \mathrm{~min}$, followed by determining the absorbance $(A s)$ at $536 \mathrm{~nm}$. The reaction system without TFZB was employed as blank control $\left(A_{0}\right)$ and the one without $\mathrm{H}_{2} \mathrm{O}_{2}$ was defined as normal control $(A c)$. Vc solutions (the concentration ranging from 0 to $2 \mathrm{mg} / \mathrm{mL}$ ) were employed as positive control. The ability to scavenge hydroxyl radical was assessed as the following formula:

$$
\text { Hydroxyl radical Scavenging rate }(\%)=\frac{A s-A o}{A c-A o} \times 100
$$

\section{Reducing Power Measurement}

Reducing power of TFZB to ferric iron was measured based on the reports (Chen and Yen, 2007) with slightly modifications. About $1 \mathrm{~mL}$ of TFZB solution of different concentrations $(0.5 \sim 2.0 \mathrm{mg} / \mathrm{mL})$ was mixed with $2.5 \mathrm{~mL}$ of $0.2 \mathrm{~mol} / \mathrm{L}$ phosphate buffer $(\mathrm{pH} 6.6)$ and $2.5 \mathrm{~mL}$ of $1 \%(\mathrm{w} / \mathrm{v}) \mathrm{K}_{3}\left[\mathrm{Fe}(\mathrm{CN})_{6}\right]$ solution subsequently, followed by being incubated at $50^{\circ} \mathrm{C}$ for $20 \mathrm{~min}$. Then $2.5 \mathrm{~mL}$ of $10 \%(\mathrm{v} / \mathrm{v})$ trichloroacetic acid was added and the mixture was centrifuged at $3000 \mathrm{rpm}$ for $10 \mathrm{~min}$. A $5 \mathrm{~mL}$ of supernatant was mixed with $4 \mathrm{~mL}$ of distilled water and $1 \mathrm{~mL}$ of $0.1 \%(\mathrm{w} / \mathrm{v}) \mathrm{FeCl}_{3}$ solution and then the absorbance was read at $700 \mathrm{~nm}$ after $10 \mathrm{~min}$. $\mathrm{V}_{\mathrm{C}}$ solution with different concentrations $(0.5 \sim 2.0 \mathrm{mg} / \mathrm{mL})$ was employed as positive control.

\section{The Effects of TFZB on Strawberry Preservation}

\section{The Preparation of Strawberry Sample}

The fresh strawberries (weigh of $15 \pm 0.5 \mathrm{~g}$ for each) were divided into four groups $(n=600 \mathrm{~g})$, two groups of which were uniformly sprayed with sterilized distilled water, named blank control and the other two groups were uniformly sprayed with $0.5 \mathrm{mg} / \mathrm{mL}$ TFZB solution, named test sample (the volume of TFZB solution sprayed on each sample was approximately $100 \mathrm{~mL}$ ). The blank controls and test samples were stored at $4^{\circ} \mathrm{C}$ and room temperature, respectively. The weightlessness rate, rotting rate and $\mathrm{Vc}$ content of each treatment were determined at 1, 2, 4, 6 and 9 days (Cui et al., 2020).

\section{Weightlessness Rate Measurement}

The weight of strawberry before storage was weighed by the electronic balance (accuracy, 0.0001g), denoted as $G_{0}$ and the weight of strawberry after storage, denoted as $G_{1}$, then the weightlessness rate was calculated by the following formula:

Weightlessness rate $(\%)=\frac{G_{0}-G_{1}}{G_{0}} \times 100$

\section{Rotting Rate Measurement}

The rotting rate was evaluated by the previously mentioned method (Bhat and Stamminger, 2015) with some modifications. The appearance of mildew on the fruit surface was taken as the discriminant basis of rotting. According to the size of the rotting area, the extent of rotting was defined as four levels: 
- $\quad$ One-level of rotting fruit means:

$0<$ the rotting area $\leq 1 / 8$ area of fruit surface

- Two-level of rotting fruit means:

$1 / 8<$ the rotting area $\leq 1 / 4$ area of fruit surface

- Three-level of rotting fruit means:

$1 / 4<$ the rotting area $\leq 3 / 8$ area of fruit surface

- Four-level of rotting fruit means:

$3 / 8<$ the rotting area $\leq 1 / 2$ area of fruit surface

Then the rotting level was denoted as $A$, the number of strawberries at corresponding level was denoted as $B$, the total number of samples examined was denoted as $C$ and the total rotting rankings were defined as 4 hierarchies (One-level Four-level), then the rotting rate was calculated by the following formula:

Rotting rate $(\%)=\frac{\sum(A B)}{4 C} \times 100$

\section{Vc Content Measurement}

$\mathrm{Vc}$ content measurement was investigated by the previously reported method (Bhat and Stamminger, 2015) with some modifications. As much as $20 \mathrm{~g}$ of samples were used in the test to record the actual weight $(M)$. After being mashed, the strawberry seriflux was mixed with 20 $\mathrm{mL}$ of $1 \% \mathrm{HCl}$ solution (v/v, extraction agent) and shook well. Then the strawberry seriflux was centrifuged and 1 $\mathrm{mL}$ of supernatant $\left(V_{1}\right)$ was diluted to $100 \mathrm{~mL}\left(V_{2}\right)$ with $1 \% \mathrm{HCl}$ solution and the absorbance (A) was measured at $243 \mathrm{~nm}$. Two milliliters of $1 \% \mathrm{HCl}$ solution was employed as blank solution, while $\mathrm{Vc}$ solution at different concentrations ranged from 0.002 to $0.01 \mathrm{mg} / \mathrm{mL}$ was used as positive control. The regression equation using $\mathrm{Vc}$ as standard substance was expressed as below:

$$
A=105.75 x-0.0657\left(R^{2}=0.9901\right)
$$

The $V c$ content was calculated by the following formula:

$V c(u g / g)=\frac{x V}{M} \times \frac{V_{2}}{V_{1}}$

Where:

$x=$ The concentration of $\mathrm{Vc}(\mu \mathrm{g} / \mathrm{mL})$

$V=$ The volume of the extraction agent $(\mathrm{mL})$

$M=$ The weight of the strawberry $(\mathrm{g})$

$V_{1}=$ The volume of the supernatant of strawberry seriflux (mL)
$V_{2}=$ The constant volume diluted with $1 \% \mathrm{HCl}$ solution $(\mathrm{mL})$

\section{Statistical Analysis}

Data were showed as means or means \pm SD (Standard Deviation). SPSS19.0 Software (SPSS Inc., Chicago, USA) was applied to assess the statistical differences using $t$-test or one-way Analysis Of Variance (ANOVA).

\section{Results and Discussion}

Optimization of CAE Parameters for TFZB Extraction

Effects of Cellulase Dosage, Solid-to-Liquid Ratio and Ethanol Concentration on the Extraction Yield of TFZB

The effects of cellulase dosage $(0.2 \sim 0.6 \%$, w/w) on TFZB extractions were tested and the results are showed in Fig. 1a, as shown in it, TFZB extraction rate increased dramatically with the increase of cellulase dosage in the range of 0.2 to $0.4 \%$ and reached a peak of $0.45 \pm 0.007 \%$ at $0.4 \%$ dosage, but obviously decreased within the range of 0.4 to $0.6 \%$. These results suggested that cellulase could promote the release of TFZB by the way of destroying cellulose in the cell wall, however, the decrease of TFZB yield with further increasing amount of cellulase could be due to the fact that all the binding sites on the cell walls of test samples were dominated by cellulase and excessive cellulase could make the solution viscous, which is not beneficial for the enzymatic hydrolysis (Huang et al., 2016).

The ethanol concentration was also conducted and the results were showed in Fig. 1, TFZB extraction rate increased slowly with the increase of ethanol concentration in the range of 40 to $50 \%$, but, followed by decreasing dramatically with the further increase of ethanol concentration. Too high or too low ethanol concentrations are both adverse to the ideal extraction of flavonoids, which depends on the types of flavonoids in the extracts and the polarity of ethanol solution (Wei et al., 2012).

The effects of solid-to-liquid ratio $(1: 20 \mathrm{~g} / \mathrm{mL} \sim 1$ : $60, \mathrm{~g} / \mathrm{mL}$ ) on TFZB extractions were examined and the results are provided in Fig. 1c, as shown in it, TFZB extraction rate increased dramatically with the increase of solid-to-liquid ratio in the range of 1: $20 \mathrm{~g} / \mathrm{mL} \sim 1: 40$ $\mathrm{g} / \mathrm{mL}$ and then declined gradually. The increase of TFZB yield may be due to the fact that the over-increasing contact areas between the liquid and the material may result in the decrease of mass transfer resistance (Najafian, 2013). The decrease of TFZB yield perhaps could be attributed to the changes of extraction polarity with the increasing amount of solvent, which would reduce the solubility of some flavonoids in TFZB (Wei et al., 2012). Thus, the optimum solid-to-liquid ratio for TFZB extraction was deemed to be 1: $40 \mathrm{~g} / \mathrm{mL}$. 
(a)

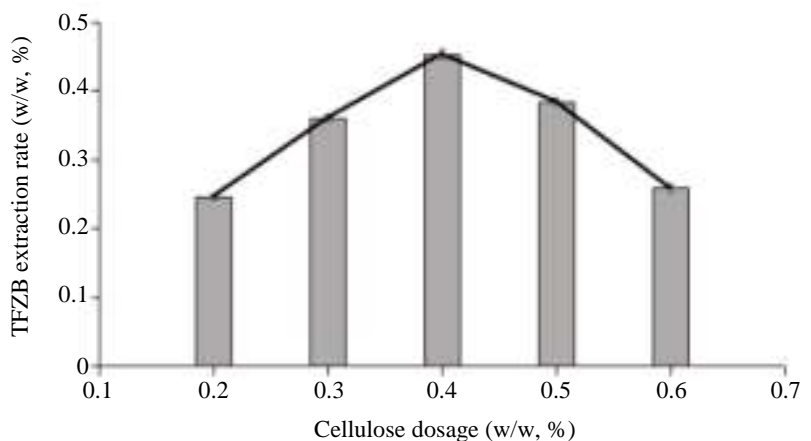

(b)

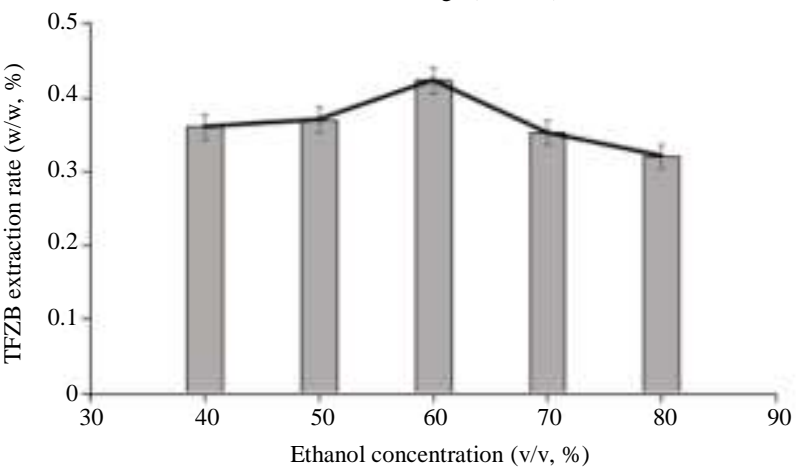

(c)

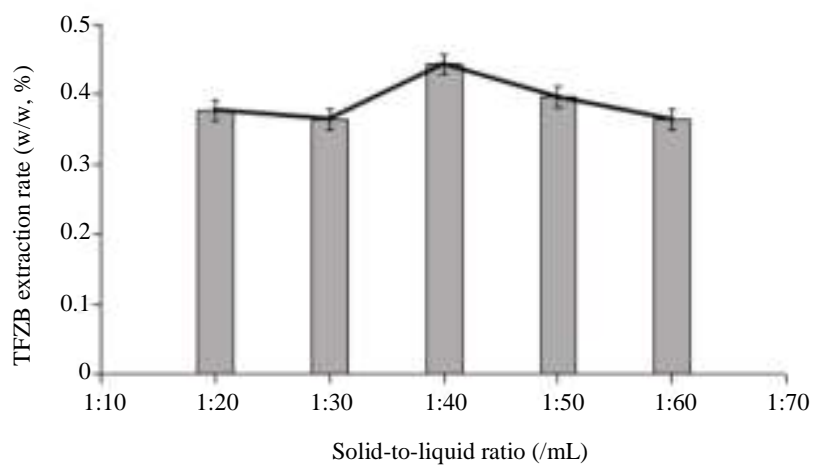

Fig. 1: The effect of single factors on the extraction of TFZB. (a) Cellulase dosage (b) Ethanol concentration (c) Solid-to-liquid ratio. Data was shown as means \pm SD $(n=3)$

\section{RSM Analysis}

The extraction of TFZB was optimized by RSM. Table 2 listed the code and actual levels of three factors including cellulase dosage $\left(X_{1}\right)$, ethanol concentration $\left(X_{2}\right)$ and solid-to-liquid ratio $\left(X_{3}\right)$ and used in the process of this assay. A total of 17 experimental combinations including 5 zero-point experiments and 12 factorial tests and response values $(Y)$ were reported in Table 2.

The response variable $Y$ (TFZB extraction rate) could be related by the following quadratic polynomial regression equation:

$$
\begin{aligned}
& Y=0.09+1.89375 X_{1}+0.00025 X_{2}+0.0076 X_{3} \\
& +0.0019 X_{1} X_{2}-0.005 X_{1} X_{3}-0.000019 X_{2} X_{3} \\
& -2.06250 X_{1}^{2}-0.0000125 X_{2}^{2}-0.00004375 X_{3}^{2}
\end{aligned}
$$

Where:

$Y=$ TFZB extraction rate $(\mathrm{w} / \mathrm{w}, \%)$

$X_{1}=$ Cellulase dosage $(\mathrm{w} / \mathrm{w}, \%)$

$X_{2}=$ Ethanol concentration $(\mathrm{v} / \mathrm{v}, \%)$

$X_{3}=$ Solid-to-liquid ratio $(\mathrm{g} / \mathrm{mL})$

The one-way Analysis Of Variance (ANOVA) for the regression equation was exhibited in Table 3 , the $P$ value of the model was $<0.0001$ and the lack of fit was $0.3258(>0.05)$, indicating that the mathematical model obtained was highly significant. The determination coefficient value (Adj- $\mathrm{R}^{2}$ ) of the model was 0.9598 , suggesting that $95.98 \%$ of the response variable could be clarified by the model. In this model, the linear coefficients $\left(X_{1}, X_{2}\right.$ and $\left.X_{3}\right)$, the interaction terms $\left(X_{1} X_{3}\right)$ and the quadratic coefficients $\left(X_{1}^{2}\right)$ were highly significant $(P<0.01)$. The quadratic 
terms $\left(X_{3}^{2}\right)$ was significant effects $(P<0.05)$. The interaction terms $\left(X_{1} X_{2}, X_{2} X_{3}\right)$ and the quadratic coefficients $\left(X_{2}^{2}\right)$ were not significant $(P>0.05)$. The $F$ value of the model is directly proportional to the response variable (Sheng et al., 2013). Thus, the influence of various factors on the extraction rate of TFZB was: $X_{1}>X_{2}>X_{3}$. In addition, the interaction effects of $X_{1} X_{2}, X_{1} X_{3}$ and $X_{2} X_{3}$ were analyzed (Fig. 2). The steepness of the response surface is directly proportional to the significance of the interaction and the ellipticity of the contour map can also directly reflect the strength of the interaction. The larger the ellipticity of the contour, the more significant the interaction is (Sheng et al., 2013). As shown in Fig. $2 \mathrm{~b}$ and Fig. $2 \mathrm{~d}$, the response surfaces were smooth and the contour line Fig. $2 \mathrm{a}$ and $2 \mathrm{c}$ tended to be round, which indicated that the interaction parameters $\left(X_{1} X_{2}\right.$ and $X_{2} X_{3}$ ) had little effect on TFZB extraction rate, however, Fig. $2 \mathrm{f}$ showed that the response surface was steep and the contour line Fig. 2e tended to be oval, which indicated that the interaction parameter $X_{1} X_{3}$ had a greater effect.
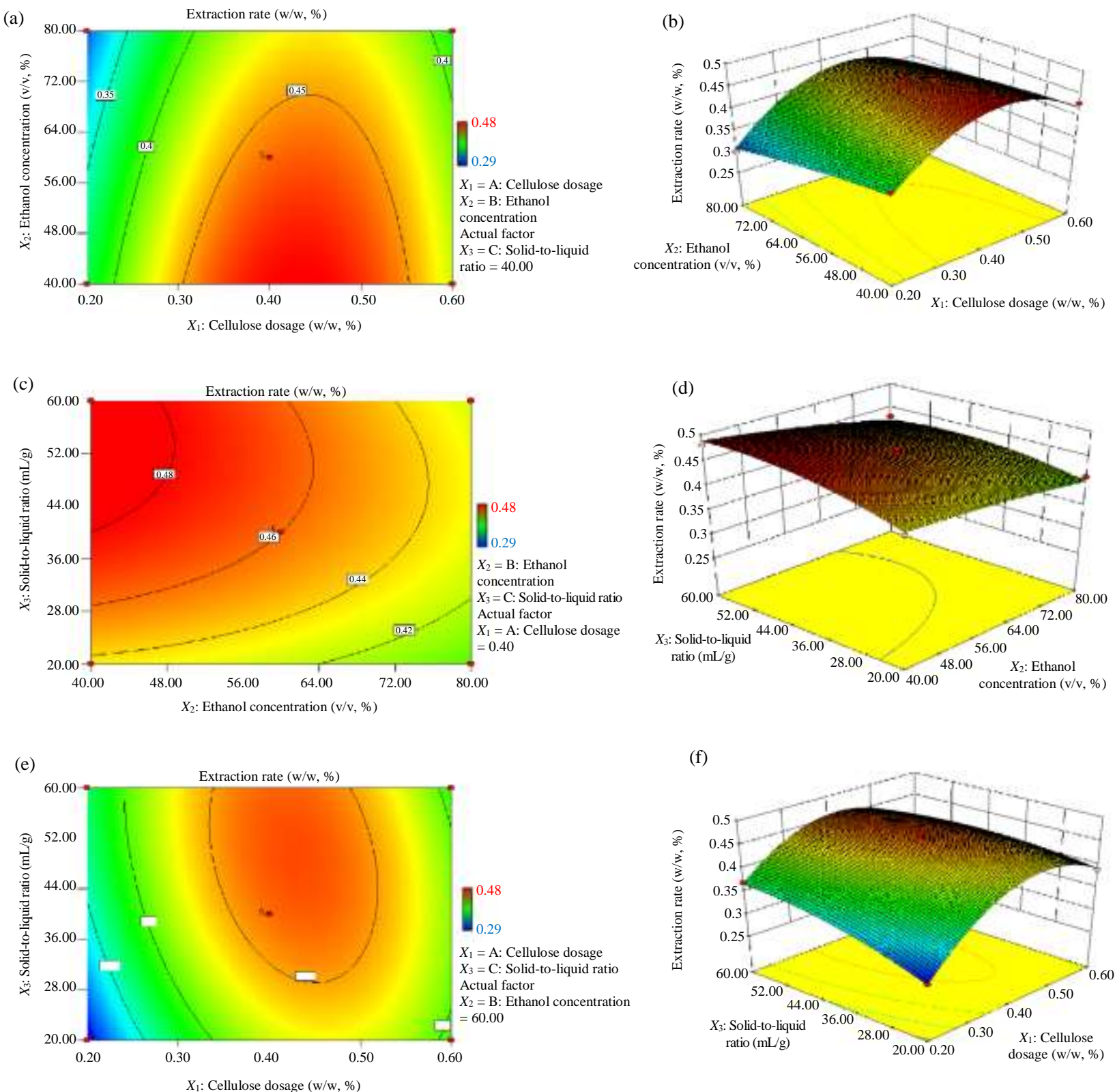

Fig. 2: Contour and surface plots showing the effects of the ratio of two factors. (a, b) Cellulase dosage versus Ethanol concentration; (c, d) Ethanol concentration versus Solid-to-liquid ratio; (e, f) Cellulase dosage versus Solid-to-liquid ratio 
Table 2: Box-Behnken design and experimental data

\begin{tabular}{|c|c|c|c|c|}
\hline \multirow[b]{2}{*}{ Run } & \multicolumn{3}{|c|}{ Independent variable } & \multirow[b]{2}{*}{$\mathrm{Y}$} \\
\hline & $\mathrm{X}_{1}$ & $\mathrm{X}_{2}$ & $\mathrm{X}_{3}$ & \\
\hline 1 & -1 & 0 & -1 & 0.37 \\
\hline 2 & 0 & 0 & 0 & 0.42 \\
\hline 3 & 0 & 0 & 0 & 0.31 \\
\hline 4 & 0 & 0 & 0 & 0.39 \\
\hline 5 & -1 & -1 & 0 & 0.29 \\
\hline 6 & 0 & 0 & 0 & 0.39 \\
\hline 7 & 1 & 1 & 0 & 0.37 \\
\hline 8 & 1 & 0 & 1 & 0.39 \\
\hline 9 & -1 & 0 & 1 & 0.44 \\
\hline 10 & 0 & 1 & -1 & 0.40 \\
\hline 11 & 0 & -1 & 1 & 0.49 \\
\hline 12 & 0 & 1 & 1 & 0.42 \\
\hline 13 & -1 & 1 & 0 & 0.46 \\
\hline 14 & 1 & -1 & 0 & 0.46 \\
\hline 15 & 0 & -1 & -1 & 0.46 \\
\hline 16 & 0 & 0 & 0 & 0.46 \\
\hline 17 & 1 & 0 & -1 & 0.36 \\
\hline
\end{tabular}

Table 3: Variance analysis of extracted equation of TFZB

\begin{tabular}{|c|c|c|c|c|c|}
\hline Source & Sum of squares & Mean square & $F$-value & $P$-value & Significance $^{a}$ \\
\hline Model & 0.049 & $5.424 \times 10^{-3}$ & 43.39 & $<0.0001$ & $* *$ \\
\hline$X_{1}$ & $7.813 \times 10^{-3}$ & $7.813 \times 10^{-3}$ & 62.50 & $<0.0001$ & $* *$ \\
\hline$X_{2}$ & $5.000 \times 10^{-3}$ & $5.000 \times 10^{-3}$ & 40.00 & 0.0004 & $* *$ \\
\hline$X_{3}$ & $2.813 \times 10^{-3}$ & $2.813 \times 10^{-3}$ & 22.50 & 0.0021 & $* *$ \\
\hline$X_{1} X_{2}$ & $2.250 \times 10^{-4}$ & $2.250 \times 10^{-4}$ & 1.80 & 0.2216 & n.s. \\
\hline$X_{1} X_{3}$ & $1.600 \times 10^{-3}$ & $1.600 \times 10^{-3}$ & 12.80 & 0.0090 & $* *$ \\
\hline$X_{2} X_{3}$ & $2.250 \times 10^{-4}$ & $2.250 \times 10^{-4}$ & 1.80 & 0.2216 & n.s. \\
\hline$X_{1}^{2}$ & 0.029 & 0.029 & 229.26 & $<0.0001$ & $* *$ \\
\hline$X_{2}^{2}$ & $1.053 \times 10^{-4}$ & $1.053 \times 10^{-4}$ & 0.84 & 0.3893 & n.s. \\
\hline$X_{3}^{2}$ & $1.289 \times 10^{-3}$ & $1.289 \times 10^{-3}$ & 10.32 & 0.0148 & $*$ \\
\hline Residual & $8.750 \times 10^{-4}$ & $1.250 \times 10^{-4}$ & & & \\
\hline Lack of fit & $4.750 \times 10^{-4}$ & $1.583 \times 10^{-4}$ & 1.58 & 0.3258 & n.s. \\
\hline Pure error & $4.000 \times 10^{-4}$ & $1.000 \times 10^{-4}$ & & & \\
\hline Cortotal & 0.050 & & & & \\
\hline Adj-R $R^{2}=0.9598$ & & & & & \\
\hline
\end{tabular}

$\mathrm{a}^{* *} P<0.01$ highly significant; ${ }^{*} P<0.05$ significant; $P>0.05$ not significant (n.s.)

\section{Verification of Predictive Model}

According to the quadratic multinomial regression equation of the extraction rate of TFZB, the optimal extraction conditions were obtained as follows: Cellulase dosage of $0.40 \%(\mathrm{w} / \mathrm{w})$, the liquid-to-solid ratio of 41.15: $1 \mathrm{~mL} / \mathrm{g}$, the ethanol concentration of $41.05 \%$ $(\mathrm{v} / \mathrm{v})$, the predicted extraction rate of TFZB was $0.48 \%$ $(\mathrm{w} / \mathrm{w})$. Considering the operability of process, the optimal extraction conditions were modified as below: Cellulase dosage of $0.40 \%(\mathrm{w} / \mathrm{w})$, liquid-to-solid ratio of 41: $1 \mathrm{~mL} / \mathrm{g}$, ethanol concentration of $41 \%(\mathrm{v} / \mathrm{v})$. The actual extraction rate of TFZB was $0.49 \pm 0.01 \%(\mathrm{w} / \mathrm{w})(\mathrm{n}$ $=3$ ), which was a $2.1 \%$ deviation compared with the model predicted. These results showed that the model has a good fitting degree and the reliability of the predictive model was also verified.

\section{In Vitro Antioxidant Activity of TFZB}

The DPPH radical-scavenging capacities of TFZB were investigated and the results was provided in Fig. 3a, as shown in it, the scavenging capacities of TFZB and Vc on DPPH radicals had a significant dose-effect relationship with the concentration ranging from 0.2 to $1.0 \mathrm{mg} / \mathrm{mL}$. The half inhibitory concentration $\left(\mathrm{IC}_{50}\right)$ values of TFZB and Vc against DPPH were 0.39 and $0.09 \mathrm{mg} / \mathrm{mL}$, respectively. Therefore, the scavenging capacities of TFZB against DPPH was close to that of $\mathrm{Vc}$ when the concentration was in the range of $0.6 \sim 1.0 \mathrm{mg} / \mathrm{mL}$, especially when the concentration was $0.8 \mathrm{mg} / \mathrm{mL}$, the scavenging capacities against DPPH were similar, both of which were $88 \%$.

The hydroxyl radical-scavenging capacities of TFZB were also investigated and the results were provided in Fig. 3b, as shown in it, the scavenging capacities of TFZB 
and Vc on hydroxyl radicals also elicited significant doseeffect relationship within the concentrations spanning from 0.4 to $2.0 \mathrm{mg} / \mathrm{mL}$. The $\mathrm{IC}_{50}$ values of TFZB and $\mathrm{Vc}$ against hydroxyl radicals were 0.70 and $0.12 \mathrm{mg} / \mathrm{mL}$, respectively, indicating that the hydroxyl radicalsscavenging capacity of TFZB is superior to that of Vc.

The reducing power of TFZB to ferric iron was also studied and the results were provided in Fig. $3 \mathrm{c}$, as shown in it, the reducing powers of TFZB and $\mathrm{Vc}$ to ferric iron also showed a dose-effect relationship within the concentrations of $0.4 \sim 2.0 \mathrm{mg} / \mathrm{mL}$ and the median effect concentration $\left(\mathrm{EC}_{50}\right)$ values of TFZB and $\mathrm{Vc}$ to ferric iron were 0.39 and $0.12 \mathrm{mg} / \mathrm{mL}$, respectively, indicating that the reducing power of TFZB to ferric iron is slightly inferior to that of $\mathrm{Vc}$.
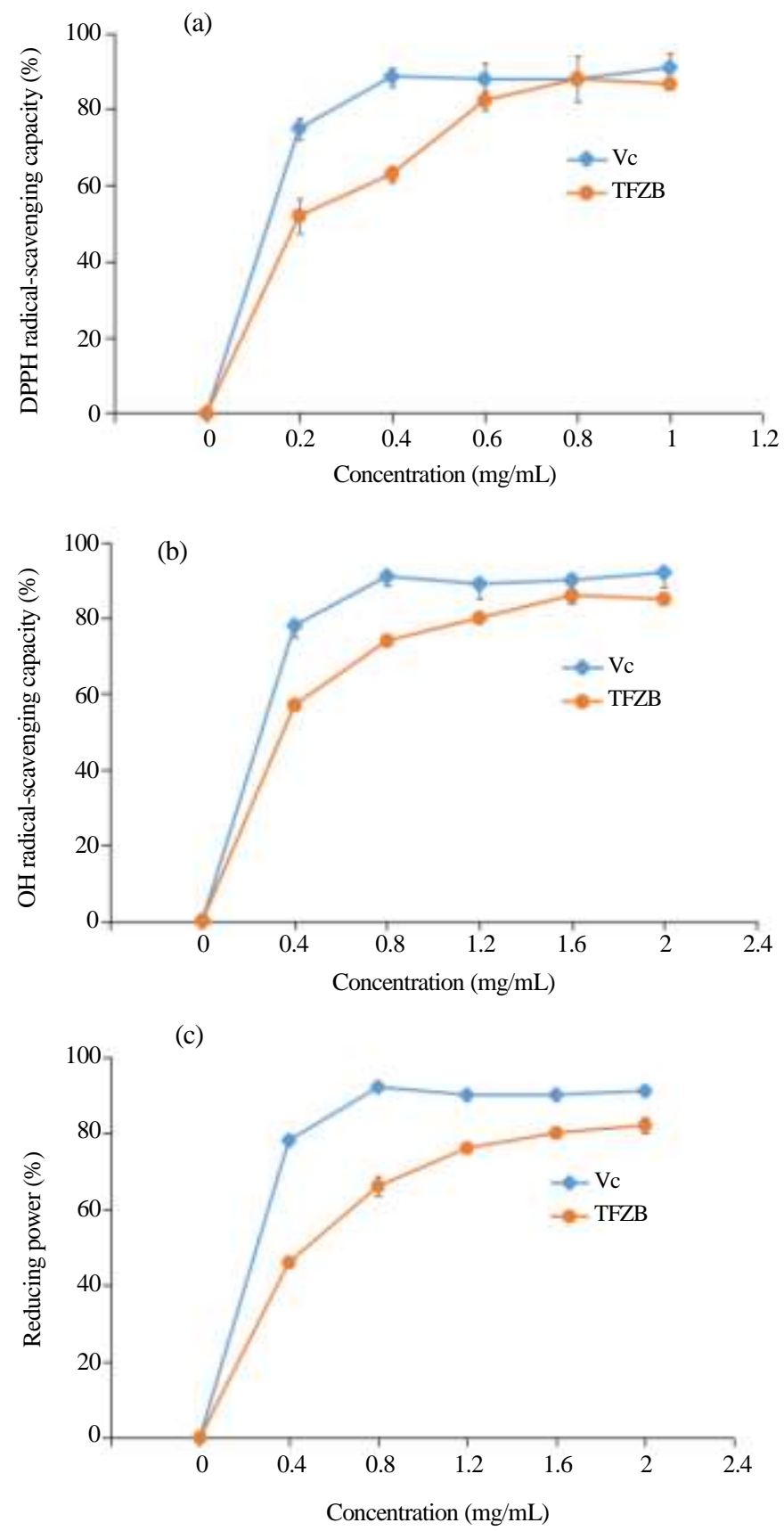

Fig. 3: The in vitro antioxidant evaluation of TFZB using Vc as positive control. (a) DPPH radical-scavenging capacities; (b) Hydroxyl radical-scavenging capacities; (c) Reducing power. Data was shown as means \pm SD $(n=3)$ 


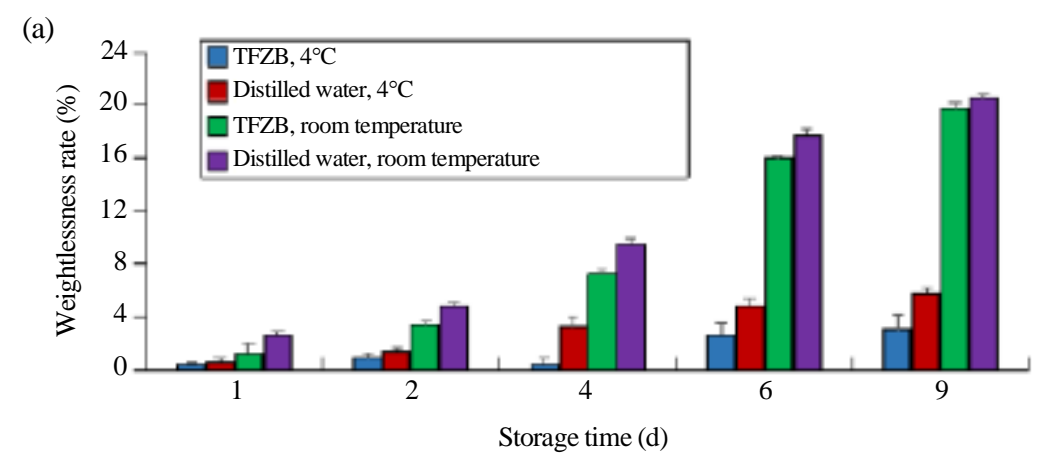

(b)

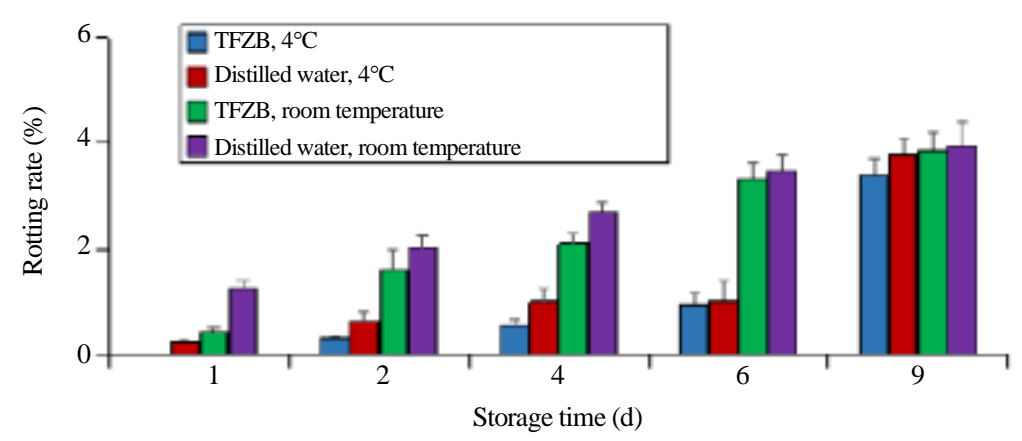

(c)

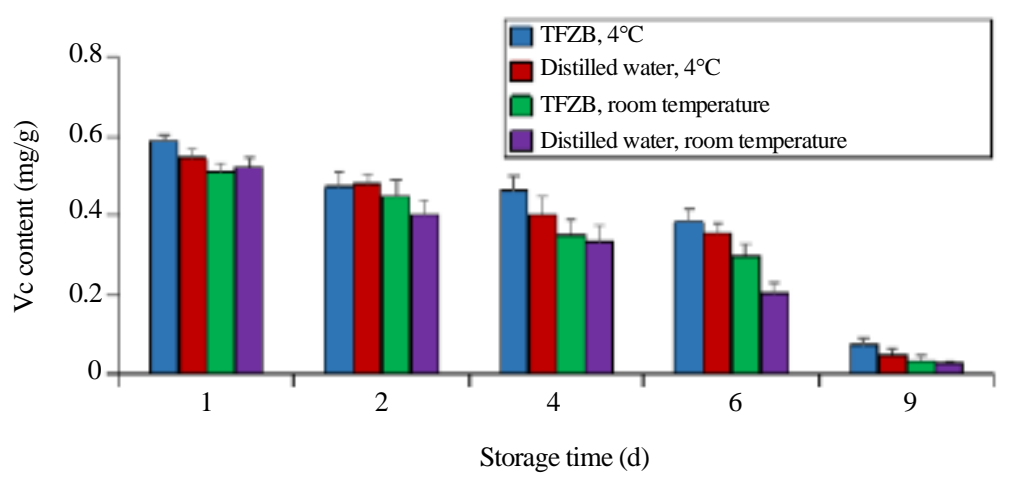

Fig. 4: The effects of TFZB on strawberry preservation (a) Weightlessness rate; (b) Rotting rate; (c) Vc content. Data was expressed as means $\pm \operatorname{SD}(n=3)$

The antioxidant capacity of compounds mainly depends on the protons that are supplied to neutralize free radicals at different reaction stages. Meanwhile, the main reason why flavonoids have antioxidant activity is that phenolic hydroxyl groups in flavonoids can react with free radicals to terminate the chain reaction. Besides, the methoxyl groups at the ortho-positions of phenolic hydroxyl in aromatic ring have a synergistic effect on the antioxidant activity and the most important active site of flavonoids are catechol hydroxyl at the position of C-3',4' (Omosa et al., 2014). According to the antioxidant analysis in this assay, the comprehensive antioxidant capacity of TFZB seems to be strong, deserving of deep investigation. However, present paper focused on the extraction optimization of TFZB, the components of TFZB are still lacking and whether there are any of the above-mentioned structures or other chemical structures that can enhance their antioxidant capacity is still unclear. In the future work, we will analyze the components of TFZB to further establish the structure-activity relationship between compound structure and antioxidant activity.

\section{Effects of TFZB on Strawberry Preservation}

The changes in weight loss of strawberries after being treated with TFZB and distilled water at room temperature and $4 \mathrm{~h}$ were determined and the results were provided in Fig. 4a, as indicated in it, the 
weightlessness rate of strawberry increased continuously with prolonging the storage time, at the same time, compared with the blank group, the weightlessness rate of strawberries slowed down when treated with TFZB at a concentration of $0.5 \mathrm{mg} / \mathrm{mL}$. The weightlessness rate at room temperature was significantly higher than that of the samples at $4^{\circ} \mathrm{C}$, which could be induced by the enhanced transpiration at higher temperature and the fast respiration rate of strawberry itself (Bhat and Stamminger, 2015). From the cellular level, Li found that the water loss during strawberry storage is caused by the increasing permeability of the cell membrane (Bhat and Stamminger, 2015). According to this hypothesis, the decrease in weightlessness rate during storage of strawberries after TFZB treatment may be due to the fact that TFZB could reduce cell damage and degeneration and maintain cell stability.

The changes in rotting rate of strawberries after being treated with TFZB and distilled water at room temperature and at $4^{\circ} \mathrm{C}$ were measured and the results were provided in Fig. 4b, as indicated in Fig. 4b, the rotting rate of strawberry also increased continuously with prolonging the storage time, meanwhile, compared with the blank group, the rotting rate of strawberries slowed down when treated with TFZB at a concentration of $0.5 \mathrm{mg} / \mathrm{mL}$. Besides, the rotting rate at room temperature was significantly higher than that of the samples at $4^{\circ} \mathrm{C}$, which could be associated with the inhibition of the growth and reproduction of microorganisms at low temperatures. Strawberry spoilage is mainly caused by various pollutions induced by molds (Han-Bing et al., 2020). Mounting evidences have pointed out that flavonoids have an inhibitory effect on microorganisms (Cui et al., 2020). Molds belong to the class of fungi. Li et al emphasized that the antifungal compounds tend to be more lipophilic. Therefore, the inhibitory effects of TFZB on the decay of strawberries observed in this assay may be contributed by the lipophilic compounds in TFZB, which could aggregate into membranes on the surface of the strawberry, thus playing a role in water retention, which was another reasonable explanation for the changes in the weightlessness rate in the assay. Hence, the antifungal potential and activitycontributed compounds, particularly lipophilic ingredients in TFZB are needed to be further explored.

The changes in $\mathrm{Vc}$ content of strawberries during storage was shown in Fig. 4c. As indicated in it, the Vc content in strawberries decreased gradually with prolonging the storage time. Surprisingly, under the same conditions, the Vc content in strawberries treated with TFZB solution was higher than that in blank control, which complies with the antioxidant capacity of TFZB. As antioxidant, TFZB could quench the free radicals on the surface of the strawberries to protect $\mathrm{Vc}$ from being destroyed.

In summary, TFZB plays a central role in strawberry preservation. However, in this assay, the concentration of TFZB solution was only selected a lower level of 0.5 $\mathrm{mg} / \mathrm{mL}$. According to the observed results that the antioxidant capacity of TFZB increased with the increase of concentration, therefore, it is speculated that increasing the amount of TFZB in strawberry preservation may have better preservation effect, which will be another focus in our future research.

\section{Conclusion}

Z. Latifolia is the second largest aquatic vegetable in China, how to reasonably utilize the discarded bracts is an urgent concern regarding the sustainable and comprehensive utilization of $Z$. Latifolia species. In present investigation, the bract of $Z$. Latifolia was taken as the research object, Total Flavonoids from $Z$. latifolia Bracts (TFZB) were extracted and optimized and the yield of TFZB reached $0.49 \pm 0.01 \%$ after the RSM optimization. Besides, TFZB exerted certain antioxidant capacity and reducing power on $\mathrm{Fe}^{3+}$. The application of TFZB in strawberry preservation was explored for the first time and the positive effects on strawberry preservation were verified by several tests. Further studies are still needed to clarify the flowing issues: (1) TFZB composition analysis and antifungal experiments are needed to be carried out to verify the association between compound structure, antioxidant and antifungal activity; (2) The preservation effect curves under different concentrations of TFZB should be constructed to determine the best preservation scheme. Nevertheless, it is hoped that this work will provide ideas for the comprehensive development and utilization of discarded Z. latifolia bracts.

\section{Funding Information}

Present investigation was supported by the Jiangsu Provincial Undergraduate Innovation and Entrepreneurship Training Programs in 2020 (Grant No. 202010333060Y and 202010333062Y).

\section{Author's Contributions}

Tong Wang and Yuzhu Zhang: Perform the extraction process optimization and draft the manuscript.

Lijie Ben, Chenxin Zhai and Ying Lv: Carry out the evaluation of antioxidant capacity and strawberry preservation.

Yang Zhang and Lixue Zheng: Design the experiments and polish the manuscript. 


\section{Ethics}

There is no ethical issue that may arise after the publication of this manuscript.

\section{References}

Bai, S., Tang, C., Tian, J., Yan, H., Xu, X., \& Fan, H. (2015). Extraction and antioxidant activity of total flavonoids from sea buckthorn pomace. Food Science, 36(10), 59-64. https://doi.org/10.7506/spkx1002-6630-201510012

Bhat, R., \& Stamminger, R. (2015). Preserving strawberry quality by employing novel food preservation and processing techniques-recent updates and future scope - an overview. Journal of Food Process Engineering, 38(6), 536-554. http://doi.10.1111/jfpe.12184

Chen, H. Y., \& Yen, G. C. (2007). Antioxidant activity and free radical-scavenging capacity of extracts from guava (Psidium guajava L.) leaves. Food chemistry, 101(2), 686-694. https://doi.org/10.1016/j.foodchem.2006.02.047

Cui, H., Dong, Y., Lu, T., Zou, X., Wang, M., Yang, X., \& Zhou, H. (2020). Effect of ethanolic extract from Morus alba L. leaves on the quality and sensory aspects of chilled pork under retail conditions. Meat Science, 172, 108368. Food Sci, 10, 59-64.rom sea buckthorn pomace. Food Sci, 10, 59-64. https://doi.org/10.1016/j.meatsci.2020.108368

Han-Bing, Z. H. U., Rui-Hu, M. I. N. G., Yuan, Z. H. A. N. G., Jia-Peng, G. U. O., Yang, L. I., \& Guo-Ping, Z. H. O. U. (2020). Isolation and Identification of Spoilage Organism in Strawberry and Screening of Antagonistic Yeast. Science and Technology of Food Industry, 41(1), 98-104. http://www.spgykj.com/article/doi/10.13386/j.issn1 002-0306.2020.01.017?pageType=en

Huang, D., Zhou, X., Si, J., Gong, X., \& Wang, S. (2016). Studies on cellulase-ultrasonic assisted extraction technology for flavonoids from Illicium verum residues. Chemistry Central Journal, 10(1), 1-9. https://doi.org/10.1186/s13065-016-0202-Z

Jiang, M. X., Zhai, L. J., Yang, H., Zhai, S. M., \& Zhai, C. K. (2016). Analysis of active components and proteomics of chinese wild rice (Zizania latifolia (Griseb) Turcz) and Indica rice (Nagina22). Journal of medicinal food, 19(8), 798-804. https://doi.org/10.1089/jmf.2015.3612

Liu, J., Mu, T., Sun, H., \& Fauconnier, M. L. (2019a). Optimization of ultrasonic-microwave synergistic extraction of flavonoids from sweet potato leaves by response surface methodology. Journal of Food Processing and Preservation, 43(5), 1-10. http://doi.10.1111/jfpp.13928
Liu, Z., Kong, L., Lu, S., \& Zou, Z. (2019b). Application of a combined homogenate and ultrasonic cavitation system for the efficient extraction of flavonoids from cinnamomum camphora leaves and evaluation of their antioxidant activity in vitro. Journal of analytical methods in chemistry, 2019. https://doi.org/10.1155/2019/4892635

Najafian, S. (2013). Rapid Extraction and Analysis of Volatile Oils Components of Melissa officinalis using Headspace and Gas Chromatography/Mass Spectrometry. Journal of herbs, spices \& medicinal plants, 19(4), 340-347. https://doi.org/10.1080/10496475.2013.799109

Omosa, L. K., Amugune, B., Ndunda, B., Milugo, T. K., Heydenreich, M., Yenesew, A., \& Midiwo, J. O. (2014). Antimicrobial flavonoids and diterpenoids from Dodonaea angustifolia. South African journal of botany, 91, 58-62. https://doi.org/10.1016/j.sajb.2013.11.012

Shao, Y., Tang, F., Huang, Y., Xu, F., Chen, Y., Tong, C., ... \& Bao, J. (2014). Analysis of genotypex environment interactions for polyphenols and antioxidant capacity of rice by association mapping. Journal of agricultural and food chemistry, 62(23), 5361-5368. https://doi.org/10.1021/jf500951e

Sheng, Z. L., Wan, P. F., Dong, C. L., \& Li, Y. H. (2013). Optimization of total flavonoids content extracted from Flos Populi using response surface methodology. Industrial Crops and Products, 43, 778-786. https://doi.org/10.1016/j.indcrop.2012.08.020

Surendiran, G., Alsaif, M., Kapourchali, F. R., \& Moghadasian, M. H. (2014). Nutritional constituents and health benefits of wild rice (Zizania spp.). Nutrition reviews, 72(4), 227-236. https://doi.org/10.1111/nure.12101

Wei, F. Y., Fang, J., Chen, W., \& Yang, Y. M. (2012). Application of bamboo leaf flavonoids for preservation of soybean milk. Food Science, 33(18), 312-315.

https://en.cnki.com.cn/Article_en/CJFDTotalSPKX201218068.htm

Winarsi, H., \& Yuniaty, A. (2019). Antioxidant Exploration in Cardamom Rhizome Potential as a Functional Food Ingredient. In IOP Conference Series: Earth and Environmental Science (Vol. 217, No. 1, p. 012019). IOP Publishing. https://doi.org/10.1088/1755-1315/217/1/012019

Yan, N., Du, Y., Liu, X., Chu, C., Shi, J., Zhang, H., ... \& Zhang, Z. (2018). Morphological characteristics, nutrients and bioactive compounds of Zizania latifolia and health benefits of its seeds. Molecules, 23(7), 1561. 
Zakaryan, H., Arabyan, E., Oo, A., \& Zandi, K. (2017). Flavonoids: promising natural compounds against viral infections. Archives of virology, 162(9), 2539-2551. https://doi.org/10.1007/s00705-017-3417-y

Zhang, H., Cao, P., Agellon, L. B., \& Zhai, C. K. (2009). Wild rice (Zizania latifolia (Griseb) Turcz) improves the serum lipid profile and antioxidant status of rats fed with a high fat/cholesterol diet. British journal of nutrition, 102(12), 1723-1727. https://doi.org/10.1017/S0007114509991036

Zhang, Y., Lu, J., Ben, L. J., Zheng, L. X., Xu, P. F., \& Jia, Y. G. (2019). Optimization of cellulase-assisted extraction of total flavonoids from corn bract and evaluation of antioxidant and antibacterial activities. American Journal of Biochemistry and Biotechnology, $\quad 15 \quad$ (2): $\quad 61-74$. https://doi.org/10.3844/ajbbsp.2019.61.74.
Zhang, Y., Shufen, L. I., Xiwen, W. U., \& Xing, Z. H. A. O. (2007). Macroporous resin adsorption for purification of flavonoids in Houttuynia cordata Thunb. Chinese Journal of Chemical Engineering, 15(6), 872-876. https://doi.org/10.1016/S10049541(08)60017-8 